\title{
Article
}

\section{Pattern Formation by Staphylococcus epidermidis via Droplet Evaporation on Micropillars Arrays at a Surface}

Susarrey-Arce, A., Marin, A., Massey, A., Oknianska, Alina, DíazFernandez, Y., Hernández-Sánchez, J. F., Griffiths, E., Gardeniers, J. G. E., Snoeijer, J. H., Lohse, Detlef and Raval, R.

Available at https://clok.uclan.ac.uk/33619/

Susarrey-Arce, A., Marin, A., Massey, A., Oknianska, Alina, Díaz-Fernandez, Y., Hernández-Sánchez, J. F., Griffiths, E., Gardeniers, J. G. E., Snoeijer, J. H. et al (2016) Pattern Formation by Staphylococcus epidermidis via Droplet

Evaporation on Micropillars Arrays at a Surface. Langmuir, 32 (28). pp. 71597169. ISSN 0743-7463

It is advisable to refer to the publisher's version if you intend to cite from the work. http://dx.doi.org/10.1021/acs.langmuir.6b01658

For more information about UCLan's research in this area go to

http://www.uclan.ac.uk/researchgroups/ and search for <name of research Group>.

For information about Research generally at UCLan please go to http://www.uclan.ac.uk/research/

All outputs in CLoK are protected by Intellectual Property Rights law, including Copyright law. Copyright, IPR and Moral Rights for the works on this site are retained by the individual authors and/or other copyright owners. Terms and conditions for use of this material are defined in the policies page. 


\section{Pattern formation by Staphylococcus epidermidis via}

\section{droplet evaporation on micropillars arrays at a}

\section{surface}

A. Susarrey-Arce, 1, A. Marin ${ }^{2}$, A. Massey ${ }^{1}$, A. Oknianska ${ }^{1}$, Y. Díaz-Fernandez ${ }^{1}$, J. F. Hernández-Sánchez $z^{3}$, E. Griffiths ${ }^{1}$, J. G. E. Gardeniers ${ }^{4}$, J. H. Snoeijer ${ }^{3,5}$ Detlef Lohse $^{3}$ and R. Raval $^{*}, 1$

${ }^{1}$ Open Innovation Hub for Antimicrobial Surfaces at the Surface Science Research Centre and Department of Chemistry, University of Liverpool, Oxford Street, UK L69 3BX, Liverpool

${ }^{2}$ Institute of Fluid Mechanics and Aerodynamics, Bundeswehr University Munich, Germany

${ }^{3}$ Physics of Fluids Group, MESA+ Institute for Nanotechnology, J. M. Burgers Centre for Fluid Dynamics, University of Twente, P.O. Box 217, 7500AE Enschede, The Netherlands

${ }^{4}$ Mesoscale Chemical Systems, MESA+ Institute for Nanotechnology, University of Twente, P.O. Box 217, 7500AE Enschede, The Netherlands

${ }^{5}$ Mesoscopic Transport Phenomena, Eindhoven University of Technology, Den Dolech 2, 5612 AZ Eindhoven, The Netherlands

\section{Corresponding author(s):}

Prof. Rasmita Raval, Phone: +44 151794 6981, e-mail: R.Raval@liverpool.ac.uk

Dr. Arturo Susarrey-Arce, Phone: +44 151794 3541, e-mail: A.Susarrey-Arce@liverpool.ac.uk

Keywords: zipping-wetting, coffee-stain, bacterial viability, microstructures, wetting 


\begin{abstract}
We evaluate the effect of epoxy surface structuring on the evaporation of water droplets containing Staphylococcus epidermidis (S. epidermidis). During evaporation, droplets with $S$. epidermidis cells yield to complex wetting patterns such as the zipping-wetting ${ }^{1-3}$ and coffeestain effects. Depending on the height of the microstructure, the wetting fronts propagate circularly or in a stepwise manner, leading to the formation of octagonal or square-shaped deposition patterns. ${ }^{4,5} \mathrm{We}$ observed that the shape of the dried droplets has considerable influence on the local spatial distribution of S. epidermidis deposited between micropillars. These changes are attributed to an unexplored interplay between the zipping-wetting ${ }^{1}$ and the coffee-stain $^{6}$ effects in polygonally-shaped droplets containing S. epidermidis. Induced capillary flows during evaporation of $S$. epidermidis are modeled with polystyrene particles. Bacterial viability measurements for S. epidermidis shows high viability of planktonic cells, but low biomass deposition on the microstructured surfaces. Our findings provide insights into design criteria for the development of microstructured surfaces on which bacterial propagation could be controlled, limiting the use of biocides.
\end{abstract}




\section{Introduction}

The production of biological and chemical materials ${ }^{7,8}$ that control the growth and survival rate of microorganisms ${ }^{9}$ at surfaces is of great interest for future antimicrobial strategies. ${ }^{10}$ An important factor affecting the development of bacterial colonies is the initial adhesion to the surface, which initiates proliferation and biofilm formation and has major impact in contamination of medical devices. ${ }^{11-14}$ For example, S. epidermidis infections can commence with the introduction of bacteria transferred from the skin during medical device insertion, and account for at least $22 \%$ of bloodstream infections in intensive care unit patients. ${ }^{15}$ It has recently been found that a surface with micro(nano)-topography in contact with microorganisms can influence microbial growth, attachment, and distribution. ${ }^{16,17}$ In addition, modifying surface topography can also create water repellent substrates, which may prevent infections by reducing bacterial growth and propagation after the evaporation of the liquid. ${ }^{10}$, 18-22 However, droplets in such superhydrophobic or hydrophobic states are energetically unstable and eventually the droplet gets impaled by the microscopic structure, losing the hydrophobic character ${ }^{23-26}$ and causing the liquid to infiltrate the structure. Such a transition can however be avoided with suitable engineered micropatterned substrates ${ }^{27-29}$ with sharpedged pillars ${ }^{30-32}$ or with relatively high microstructures. ${ }^{33-35}$ In addition, the spreading of the liquid front is also affected by the pillar geometry, leading to a droplet footprint with a polygonal shape. This phenomenon has been termed zipping-wetting and it has been observed for submillimetric-structures. ${ }^{4,5}$ As well as forming elaborately patterned footprints on surfaces, ${ }^{36-40}$ the dried pattern can have profound effect on the distribution and survival rate of bacteria on a substrate. However, little is known about how the presence of bacteria in droplets affects the drying on microstructured surfaces and how the bacterial interaction at the wetting front affects the resulting bacterial deposition over the substrate. This problem can be compared to the behavior of particle suspension droplets, which, upon evaporation, have been shown to 
leave distinct ring-shaped marks on the surface. This phenomenon is known as coffee-stain effect whereby the colloidal particles are deposited around the perimeter of a droplet. ${ }^{6,41}$

In this paper we assess the effect of epoxy surface structuring on the evaporation of bacteriacontaining droplets and the resulting bacterial distribution on the microstructured surfaces. First, S. epidermidis wetting patterns are studied. Our experiments show an interesting combination of the zipping-wetting and the coffee-stain effect that has not been previously explored for bacterial-containing droplets. The combination of these two phenomena leads to a breakdown of the droplets axial symmetry which directs the distribution of bacteria along and outside the droplet perimeter. Second, the local distribution of $S$. epidermidis cells deposited between individual micropillars is studied. Our results reveal that the proportion of the resulting local bacterial patterns can be modified by varying the pillar height of the fabricated microstructures. Third, S. epidermidis viability is studied and shows that in spite of high viability of planktonic cells re-grown over the substrates, biofilm formation over these surfaces is relatively impaired. These effects could be attributed to the local bacterial distribution over microstructured substrates. Finally, to quantify the dynamics of the $S$. epidermidis deposition, polystyrene (PS) particles are used. PS particles resembled the capillary driven flows during the zipping-wetting and the coffee-stain effects. 


\section{Methods}

2.1 Deep Reactive-Ion Etching of Silicon. Photolithographically defined silicon micropillar arrays were produced with Deep Reactive Ion beam Etching (DRIE) as described in detail elsewhere. ${ }^{27,31}$ In a DRIE system (Adixen AMS100-SE), with a RF generator at $13.56 \mathrm{MHz}$, CCP $80 \mathrm{~W}$ LF and $1500 \mathrm{~W}$ ICP plasma source, the micropillar arrays were etched by keeping the total chamber pressure at 75 mTorr. The temperature of the electrode with the silicon substrate was kept at $10{ }^{\circ} \mathrm{C}$, using liquid nitrogen as a coolant. The etching time was varied from 1.5 min to 5 min to obtain pillar heights of approximately 5 (H5), $10(\mathrm{H} 10)$ and 15 (H15) $\mu \mathrm{m} . \mathrm{SF}_{6}$ and $\mathrm{C}_{4} \mathrm{~F}_{8}$ flows were kept constant during the etching process at $250 \mathrm{sccm}$ (standard cubic centimeter per minute) and $200 \mathrm{sccm}$, respectively. After the silicon etching, photoresist and fluorocarbons were stripped in $\mathrm{O}_{2}$ plasma at $500 \mathrm{~W}$ for $30 \mathrm{~min}$, a subsequent $1 \% \mathrm{HF}$ treatment was used to remove formed $\mathrm{SiO}_{2}$.

2.2 Fabrication of polydimethylsiloxane (PDMS) molds. Prior to the fabrication of PDMS molds, vapor deposition of trichloro $(1 \mathrm{H}, 1 \mathrm{H}, 2 \mathrm{H}, 2 \mathrm{H}$-perfluorooctyl) silane (FOTS from Fluorochem) was carried out in a vacuum system for $3 \mathrm{~min}$. A negative replica of the pillar substrate was produced by casting PDMS (Dow Sylgard 184 Silicon elastomer) onto the silicon etched substrate described in section 2.1. To cure the PDMS, a 1:10 ratio of the curing agent and the pre-polymer were mixed, degassed and incubated at $85{ }^{\circ} \mathrm{C}$ for $3 \mathrm{~h}$. The PDMS mold was removed from the silicon substrate and cut prior to use. The PDMS mold was then cleaned extensively with ethanol and isopropanol, dried and treated in air plasma for $1 \mathrm{~min}$ in a Femto Diener plasma cleaner (Zepto model).

2.3 Fabrication of epoxy micropillars. Epoxy micropillars were produced by casting EPOTEK (OG142-13 from Epoxy Technology) onto the negative PDMS replica described in section 2.2. After Epoxy was cast, a glass slide was placed over the PDMS substrate with 
Epoxy material. The epoxy was cured using Ultraviolet light. A UVL-56 Handheld UV lamp was used (6 Watt and wavelength of $365 \mathrm{~nm}$ ) for $30 \mathrm{~min}$ followed by incubation at $30{ }^{\circ} \mathrm{C}$ for $30 \mathrm{~s}$.

2.4 Configuration of micropillars on epoxy substrates. Epoxy micropillars were fabricated by casting and curing epoxy glue on a negative PDMS micropillar-replica as described in section 2.3. These microstructures, labelled from (a) to (c), are shown in Figure 1. The diameter $(d)$ and interspacing $(i)$ were restricted in the range presented in Table $\mathbf{1}$, but the heights $(h)$ were varied from 5 to $15 \mu \mathrm{m}$. The configuration of the microstructures is in a square lattice with a periodicity $p=i+d$ with a packing fraction $\Phi$, calculated as $(\pi / 4)(d / p)^{2}$ of about 0.19 and aspect ratios $(h / d)$ of approximately 1,2 , and 3 for (a), (b), and (c), respectively. The outside walls of the micropillars are smooth at the micron-scale for all of the substrates.

\subsection{Determination of $S$. epidermidis cell viability after evaporation of bacterial suspension}

over structured surfaces. S. epidermidis (ATTC-12228) cultures were grown over night (200 $\mathrm{rpm}$, at $37^{\circ} \mathrm{C}$ ) in nutrient broth (NB) medium (Oxoid, Ltd-Thermo Fisher). The bacterial cells were adjusted to $6.3 \times 10^{6}, 8.0 \times 10^{7}$ and $5.0 \times 10^{9}$ colony forming units per milliliter $(\mathrm{CFU} / \mathrm{mL})$ in sterile deionized water.

S. epidermidis viability was carried out with Flat and structured epoxy micropillar substrates sterilized under UV light for $20 \mathrm{~min} .10 \mu \mathrm{L}$ droplets of fresh bacterial cell suspension $\left(9 \times 10^{7}\right.$ $\mathrm{CFU} / \mathrm{mL}$ in water) were deposited onto $\mathrm{H} 5, \mathrm{H} 10, \mathrm{H} 15$ and flat surfaces until complete evaporation for $30 \mathrm{~min}$. After complete evaporation, each substrate was rehydrated in $1 \mathrm{~mL}$ of $\mathrm{NB}$ and the cells were cultured for $24 \mathrm{~h}$ at $37^{\circ} \mathrm{C}$. Counting of viable cells was performed after washing the surface with $200 \mu \mathrm{L}$ of sterile phosphate-buffered saline (PBS) and serial dilutions. The experiments were performed in triplicates. 
2.6 S. epidermidis biofilm formation assay. Microtiter plate biofilm formation assay was modified from the method described by O'Toole et al. ${ }^{42}$ Briefly, S. epidermidis cultures were grown overnight $\left(200 \mathrm{rpm}\right.$, at $37^{\circ} \mathrm{C}$ ) in NB medium (Oxoid, Ltd-Thermo Fisher) and diluted to $10^{7} \mathrm{CFU} / \mathrm{mL}$ in NB. Polystyrene flat (PSflat), flat epoxy, and epoxy micropillar substrates (H5, H10, and H15) of $1 \mathrm{~cm} \times 1 \mathrm{~cm}$ were sterilized under UV light for $20 \mathrm{~min}$. The substrates were placed in wells of the 24 well microtiter plate, covered with $600 \mu \mathrm{L}$ of S. epidermidis $10^{7}$ cell suspension and incubated for $24 \mathrm{~h}$ at $37^{\circ} \mathrm{C}$. After incubation bacterial cell suspension was removed, materials were gently washed 5 times with PBS, moved to the new plate and dried. The biofilms formed were stained with $600 \mu \mathrm{L}$ of a $0.1 \%$ crystal violet for $15 \mathrm{~min}$ at room temperature (RT). Crystal violet was removed; materials were washed 5 times with sterile water and dried. For quantification of biofilms formed on the flat and structured substrates, 500 $\mu \mathrm{L}$ of absolute ethanol was added (for $15 \mathrm{~min}$ at $\mathrm{RT}$ ) to solubilize the stain and transferred to a new plate. The optical density (O.D.) $595 \mathrm{~nm}$ was measured in a UV/VIS plate reader (FilterMax F5 Multi Mode Microplate Reader, Molecular Devices). Three independent experiments were performed.

2.7 Contact angle measurements on Epoxy micropillar arrays. Contact angle measurements were performed by placing a water droplet of $2-4 \mu \mathrm{L}$ on the Epoxy substrates with the set-up presented in Figure SI-1. Evaporation occurred at room temperature $\left(21^{\circ} \pm 3{ }^{\circ} \mathrm{C}\right)$ in an atmosphere with a relative humidity of $35 \pm 5 \%$. The water was purified in a Millipore Milli-Q system which involves reverse osmosis, ion-exchange, and filtration steps $(18.6 \mathrm{M} \Omega \mathrm{cm})$. Sideview videos were captured via a CMOS camera equipped with x5-x40 magnifying lenses and with a recording time of 1-2 fps.

Contact angle measurements of water and S. epidermidis droplets on epoxy surfaces were carried out by placing a water droplet with bacteria suspension of $6.3 \times 10^{6} \mathrm{CFU} / \mathrm{mL}, 8.0 \times 10^{7}$ $\mathrm{CFU} / \mathrm{mL}$ and $5.0 \times 10^{9} \mathrm{CFU} / \mathrm{mL}$ on the epoxy substrates. After deposition, the droplets 
evaporated at room temperature. Top-view droplet evaporation images were recorded at frame rates of 10 fps with a camera (Photron Fastcam SA7) with a 50D-20x-VI lens mounted in a Nikon light-microscope. Under such conditions, 2-4 $\mu \mathrm{L}$ droplets evaporate completely in approximately $1200 \mathrm{~s} \pm 250 \mathrm{~s}$. Contact angle (CA) measurements as a function of time are shown in Figure SI-2.

2.8 Deposition of Polystyrene particles on Epoxy substrates. A $10^{7}$ particles/mL solution of FluoRed-polystyrene (PS) particles purchased from Microparticles GmbH with mean diameter of $1.2 \mu \mathrm{m} \pm 0.04 \mu \mathrm{m}$ was prepared with deionized water (Milli-Q). Droplets of $2-4 \mu \mathrm{L}$ were deposited on the epoxy substrates. Substrate inspection was performed with an inverted microscope illuminated with a continuous solid-state laser diode pumped at $100 \mathrm{~mW}$ (or a halogen light) to avoid overheating. The images were collected with a CCD camera PCO Sensicam at 1 frames per second (fps). The droplets were evaporated at $23{ }^{\circ} \mathrm{C}$ and $40 \%$ relative humidity. Under such conditions, a 2-4 $\mu \mathrm{L}$ droplet completely evaporated in approximately $1200 \mathrm{~s} \pm 250 \mathrm{~s}$. It is important to note that static contact angle of the droplets containing PS particles over substrates were very similar, all being slightly below $100^{\circ}$.

2.9 SEM and AFM characterization. Fracturing the epoxy/glass substrates with a diamond cutter, a cross sectional scanning electron microscopy (SEM) image of the fabricated epoxy micropillars was collected with accelerating voltages of $3 \mathrm{kV}$ and $\mathrm{x} 1,300$ magnification using a JSM-6610 JEOL SEM. To increase the electrical conductivity of the micropillars, prior to SEM analysis a $20 \mathrm{~nm}$ chromium layer was deposited by sputtering.

Atomic force microscopy (AFM) studies were conducted using a Keysights (formally Agilent) 5500 AFM. A droplet of bacteria suspension $\left(8 \times 10^{7} \mathrm{CFU} / \mathrm{mL}\right)$ as described in section 2.7 was applied onto the micropillar substrate and dried at room temperature. Measurements were carried out in air using intermittent contact mode (tapping mode) utilizing uncoated silicon 
NCHV cantilevers (Bruker, Santa Clara, CA). These cantilevers have typical resonance frequencies of $320 \mathrm{kHz}$ and a typical spring constant of $42 \mathrm{~N} / \mathrm{m}$ (with a tolerance of 20-80 $\mathrm{N} / \mathrm{m}$ ). Due to the pillar size, the scan rate was set to $0.1 \mathrm{~Hz}$ and $5 \mathrm{~V}$ amplitude was used for imaging. Height phase-shift images were recorded and line-fitted using PicoView software supplied by Keysights.

\section{Results and discussions}

\subsection{Substrates decorated with micropillar arrays}

We first investigated the wetting and evaporation behavior of water droplets on substrates (Figure SI-1) decorated with a pillar height of $5 \mu \mathrm{m}(\mathrm{H} 5), 10 \mu \mathrm{m}(\mathrm{H} 10)$ and $15 \mu \mathrm{m}(\mathrm{H} 15)$. After deposition, the wetting transition from Cassie-Baxter state to the Wenzel state ${ }^{24-27}$ was clearly visible for substrates $\mathrm{H} 5, \mathrm{H} 10$ and $\mathrm{H} 15$ at $t \sim 80 \mathrm{sec} \pm 40 \mathrm{sec}$. On all our samples the static CA for water was found to be $\sim 100^{\circ}\left( \pm 7^{\circ}\right)$. We measured the CA of the water droplet as a function of time. The dynamics of CA values of water on these fabricated pillars are displayed in Figure SI-2. Initial CA was $98^{\circ} \pm 6^{\circ}, 105^{\circ} \pm 5^{\circ}, 100^{\circ} \pm 7^{\circ}$ for $\mathrm{H} 5, \mathrm{H} 10$ and $\mathrm{H} 15$, respectively. Hysteresis was $20^{\circ} \pm 5,35^{\circ} \pm 8$ and $60^{\circ} \pm 15$ for $\mathrm{H} 5, \mathrm{H} 10$ and $\mathrm{H} 15$, respectively. ${ }^{43-45}$ High hysteresis is expected for wetted surfaces H5, H10 and H15. This caused by a loss on hydrophobicity followed by droplet impalement in the micropillars. High hysteresis values have also been observed for polymeric susbtrates. ${ }^{34}$ It has been reported that capillary forces applied by sessile droplets can deform elastic surfaces. ${ }^{46}$ This explains the strong hysteresis we observe for H15 surfaces in Figures SI-4(c) and (f).

During evaporation, the CA of the droplets decreases (Figure SI-2), zipping-wetting propagation is observed (shown in Figure SI-5 between $t=800$ and $930 \mathrm{sec}$ ), which has also been observed for comparable configurations. ${ }^{1-3}$ In the previous studies, the zipping-wetting effect was observed with the propagation of the fluid entering and filling the microstructures 
as seen in Figure SI-5. The zipping-wetting process of these droplets is energetically favored at low CA (e.g. $t=650 \mathrm{sec}$, see Figures SI-2 and SI-5), and it becomes more favorable for the higher pillars.

\subsection{Evaporation of $S$. epidermidis suspension over substrates with micropillars}

In order to investigate the behavior of droplets containing bacteria, three different concentrations of $S$. epidermidis suspensions $\left(6.3 \times 10^{6} \mathrm{CFU} / \mathrm{mL}, 8.0 \times 10^{7} \mathrm{CFU} / \mathrm{mL}\right.$ and $5.0 \times 10^{9}$ $\mathrm{CFU} / \mathrm{mL}$ ) were prepared as described in experimental section 2.5. The pattern of bacterial distribution after drying is affected by both the concentration of S. epidermidis in the water droplets, and the height of the pillars as presented in Figure 2. A homogeneous bacterial distribution is observed for (a) H5, (b) H10 and (c) H15 at the high concentration of bacteria (5.0x $\left.10^{9} \mathrm{CFU} / \mathrm{mL}\right)$. We hypothesize that this cell distribution is governed by a high amount of S. epidermidis agglomerates at the last moment of evaporation. A microbial adherence test to $n$-hexadecane was performed ${ }^{47}$ to estimate $S$. epidermidis hydrophobicity. This technique has been used to qualitatively estimate surface hydrophobicity of cells. ${ }^{48,49}$ Cellular interactions are assumed to be subjected to forces similar to those governing colloidal aggregations between surfaces or particles in liquid. The hydrophobic interaction forces are strongly attractive and are determined by the amount of hydrophobic/hydrophilic molecular components on $S$. epidermidis (e.g. polysaccharides or hydrophobins). From our experiments, cultured $S$. epidermidis cells reveal hydrophobicity of $58 \% \pm 5 \%$. This suggest that attractive forces for hydrophobic cells interact stronger via Van der Waals forces which could prompt agglomeration leading to aggregates during evaporation.

As the concentration is reduced to $6.3 \times 10^{6} \mathrm{CFU} / \mathrm{mL}$, the classical ring-shaped stain is not visible using only white light due to the reduced amount of bacteria. Only few bacterial clusters at the border of the stain are observed in Figure 2(a)-(c). Moreover, for the intermediated 
concentration $\left(8.0 \times 10^{7} \mathrm{CFU} / \mathrm{mL}\right)$ an accumulation of bacteria in the center of the octagonal shape was observed alongside bacterial distribution at the borders (Figure 2(b)). This implies that the final evaporation patterns depend on a sensitive balance between bacteria and capillary interactions during the final stages of evaporation. It is important to note that in the current conditions Marangoni flow is much smaller than the dominant evaporation-driven flow. ${ }^{50,51}$

The Zipping-wetting effect was also observed for S. epidermidis containing droplets. Figure 3 shows a top-view image of a droplet containing S. epidermidis deposited over H15. An irregular octagon was observed until $t \sim 700 \mathrm{~s}$, after which the droplet changes into a square shape, as the fluid fills the cavities between the micropillars. It is observed that at $t=960 \mathrm{~s}$, the liquid spread out from the corners of the droplet with the formation of a cross structure stretching outside the square pattern at $t=1120 \mathrm{~s}$. Similar effects were also observed for evaporating droplets with higher bacterial concentration (e.g. 5.0x $\left.10^{9} \mathrm{CFU} / \mathrm{mL}\right)$ see supporting video $\mathbf{H 1 5}$.

To evaluate both, the zipping-wetting and the coffee stain effects during evaporation of droplets containing S. epidermidis, we studied the distribution of the localized bacterial patterns as well as bacterial cells viability. An intermediate bacterial concentration of $\sim 8.0 \times 10^{7} \mathrm{CFU} / \mathrm{mL}$ was chosen for the work in the following sections as this gave a clear visualization of the dried bacterial patterns (Figure 2).

\subsection{Localized S. epidermidis deposition environments between micropillars}

We investigated the localized environment of the bacteria within the troughs of the micropillars after evaporation using the entire droplet area (i.e. droplet perimeter and center of the droplet). Figure 4(a) shows a top-view illustration of a square lattice composed by four micropillars (grey dots) with bacteria (red dots) in the troughs. Different local bacterial environments between pillars are depicted as follows: a completely filled structure (red box); a square lattice 
with four filled edges and an empty central space, "O" shape (green box); a three sided deposition with bacteria in "C" shape (purple box); a two sided "L" shape bacterial distribution (blue box); and, finally, a single line ("I") of bacteria (pink box). A top-view bright field modular microscope image of a micropatterned substrate with deposited S. epidermidis is shown in Figure $4(\mathbf{b})$ highlighting the different kinds of local environments that are experimentally observed for the bacteria. It can be seen that all five environments are observed, highlighted with an arrow of the same color as used in Figure 4(a). In contrast to the structured surfaces, flat epoxy surfaces do not contain similar well-defined localized bacterial configurations. For comparison, a representative image of dried bacteria patterns on a flat epoxy surface is presented in Figure SI-7.

To establish the detailed distribution of bacteria suggested from the light microscope data, AFM images were collected. Due to limitation of the depth that can be probed by the AFM, imaging was only used to identify the deposition of the bacteria on substrate H5 (Figure 1(a)). The AFM data in Figure 5 shows that a high proportion of S. epidermidis cells were found at the bottom of the troughs in the space between pillars and a significantly smaller population of bacteria was found on top of the pillars. AFM images were processed to enhance the contrast between the floor (purple color), deposited bacteria (light blue colors) and top of pillars (red color).

AFM image on Figure 5 clearly shows that the deposition shapes observed by light microscopy in Figure 4(b). This can be directly attributed to the local environment and deposition pattern of the bacteria (Figure 2(a)). We have therefore mapped the statistical distribution of the different local environments of the deposited bacteria as the pillar height of the substrate is changed (shown in Figure 4(c)). It can be seen that the H5 and H10 distribution is comparable, with a similar distribution for the "O", "C" and "L" environments (each approximately $15 \%$ of the total number of patterns). In contrast, the $\mathrm{H} 15$ has a much higher concentration of 
completely filled troughs and much fewer low-concentration local environments. H5 and H15 show opposite behavior, with the taller substrate forming high-concentrations of local environments and vice-versa, while $\mathrm{H} 10$ can be considered an intermediate case. Therefore, the discussion is focused on substrates H5 and H15. Note that proportion of localized $S$. epidermidis environments shown in Figure 4(c) are collected from three independent experiments using the entire area of five dried droplets.

For H5 in Figure 4 (c), the highest proportion of the bacterial environments were found for clusters in "I" shaped environments ( $c$ a. 33\% of deposition environments), whereas for H15, a sevenfold decrease in the proportion of "I" shaped environments is observed. Moreover, there is an increase in the proportion of totally filled and "O" shaped local environments seen for the H15 substrate when compared to H5 substrates (37\% of the total number of environments for H15 compared to $14 \%$ for H5). These results confirm that the induced bacterial deposition environments can be tuned by changing the pillar heights. We suggest that the observed distribution of $S$. epidermidis in Figure $4(\mathbf{c})$ can be associated with capillary flow of the evaporated droplets. Thokchom et al. have reported that motile and nonmotile cells can be directed with the formation of ring deposits on uncoated substrates. ${ }^{52}$ Moreover, S. epidermidis preferential cell attachment to the lower areas between pillar troughs has also been reported ${ }^{22}$ and we confirm here this observation. This implies that our localized bacterial environments are actively driven by the flow during evaporation and not by the nonmotile microorganism. It is important to mention that S. epidermidis configurations may also vary in their size and shape adapting to the configuration of the decorated surface.

To assess how the local environment affects bacterial growth, bacterial viability of planktonic cells after rehydration was measured and is shown in Figure 4(d). H5 shows slight bacterial growth inhibition compared to flat, $\mathrm{H} 10$ and $\mathrm{H} 15$ substrates. We hypothesize that H5 sample contains a larger proportion of smaller local environments which could be more vulnerable to 
dehydration and cell death when compared to the larger local environments which are more prevalent on the H15 sample.

Biofilm formation assays were performed for S. epidermidis deposited over surfaces. ${ }^{42}$ This method provides additional insights on the antibacterial performance of structured materials by estimating the bacterial biomass formed on surfaces. Here, polystyrene flat surface (PSflat), flat epoxy surface (Flat), and H5, H10 \& H15 epoxy substrates were used. In Figure 6(a), we present optical density (O.D.) values. Representative images of a well plate for each surface are also presented. Images were recorded after crystal violet staining for PSflat, Flat, H5, H10 \& H15. High levels of S. epidermidis biofilm mass are found for the PSflat substrate with an O.D. 0.45. A substantial reduction of biofilm mass is obtained for Flat, H5, H10 and H15 epoxy substrates. The lowest O.D. values are $~ 0.12$ for Flat and H5, while H10 and H15 are 0.17 and 0.25 , respectively. From our biofilm mass optical density assay, measured as intensity reduction of a light beam transmitted through the biofilm, we have correlate the formed biofilm mass, measured as total carbon and as cell mass. Biofilm formation assay shows clearly the importance of both chemical composition of the material and surface topography. It has been demonstrated that staphylococci show great versatility to adhere to polymers, like polystyrene materials. ${ }^{53}, 54$ Thus, when compared to PSflat substrate (i.e. highest biofilm mass), epoxy surfaces reveal promising material properties which could reduce biofilm mass deposition. Interestingly, in spite of high S. epidermidis viability in planktonic state (Figure 4(d)), biofilm formation over epoxy surfaces is relatively impaired. It is clear that S. epidermis viability can only be affected by the surface topography since no additional surface functionalization was performed. High levels of viable cells have also been observed for functionalized and nonfunctionalized surfaces, whereas the topographic surface remains with fewer bacterial cells. ${ }^{55}$

To assess the effect of surface topography and its ability to reduce S. epidermidis attachment, biofilm mass values from Figure 6(a) were normalized to the engineered roughness index 
$\left(\right.$ ERI) in Figure 6(b) ${ }^{56,57}$ ERI (i.e. ERI $\left.=(r \times \mathrm{d} f) / f_{\mathrm{D}}\right)$ is a dimensionless value used to characterize surfaces with engineered topographies ${ }^{58}$ which solely considers the micropillar geometry, the spatial arrangement of the microstructured substrate, and the size of the topological features. ERI equation comprises of three parameters, the Wenzel's roughness factor $(r)$ which is defined as the ratio of the actual surface area to the projected planar surface area, ${ }^{59,60}$ the depressed surface fraction $\left(f_{\mathrm{D}}\right)$ as the ratio of the recessed surface area between the protruded features and the projected planar surface area, ${ }^{58}$ and the degree of freedom of movement of the microorganism of the recessed areas $(\mathrm{d} f){ }^{56-58}$

From ERI equation, values for structured substrates were 2.9, 4.8, and 6.7 for H5, H10, and H15, respectively and the ERI value for flat surfaces (i.e. PSflat and Flat) was 2. Figure 6(b) shows that PSflat substrate has the highest normalized biofilm mass. Compared to Flat surface, PSflat has $\sim 75 \%$ more formed biofilm mass. Moreover, H5, H10 \& H15 substrates shows a $\sim 50 \%$ reduction in normalized biofilm mass compare to Flat epoxy substrate. From results in Figure 6(b), no significant differences are observed between H5, H10 and H15. However, S. epidermidis attachment to $\mathrm{H} 5, \mathrm{H} 10$ and $\mathrm{H} 15$, is observed to be reduced when is normalized to the geometrical features of the fabricated substrates. Similar trends have been also achieved when O.D. is normalized to total surface area for H5, H10 and H15. From ERI analysis, beyond a quantitative assessment, we have obtained understanding of cell-feature interaction which highlights the importance of the topography on cell attachment.

Two approaches have been used to estimate the antibacterial properties of surfaces. For evaporated droplets, a small decrease in $\mathrm{H} 5$ bacterial viability is observed after rehydration and planktonic cell colony counting (Figure 4(d)). Compared to PSflat, low level of biofilm formed on epoxy substrates is observed in Figure 6(a). These results show that, regardless surface geometry, epoxy surfaces like Flat and H5 have promising antibacterial performance. For future geometrical designs, H5 substrate has shown the most desirable antibacterial properties 
capable of reducing bacterial re-growth (Figure 4(d)) and bacterial biomass formation (Figure 6(a)).

\subsection{Drying of droplets with PS particles}

The bacterial patterns described in previous sections correspond to the last stage of the deposition process. In order to understand better such deposition patterns, we perform experiments with PS particles with a mean diameter of $1.2 \mu \mathrm{m} \pm 0.04 \mu \mathrm{m}$ which is comparable to $S$. epidermidis cell diameter $(0.5$ to $1.5 \mu \mathrm{m})$. The fluorescent labelling of the PS particles allows us to observe how the deposition occurs during the evaporation process.

Experiments are performed on substrates H5, H10 and H15. PS particles concentration was $10^{7}$ particles/mL, which is comparable to the intermediate concentrations used for S. epidermidis in section 3.3. First instants of the droplet life time are dominated by the zipping-wetting effect, i.e. the contact line spreads in a step-wise manner through the pillars (e.g. Figure SI-5). As a consequence of this phenomenon, the droplet perimeter adopts a polygonal shape. As the pillar height increases from $\mathrm{H} 5$ to $\mathrm{H} 15$ the corners of the droplet footprint become more squared.

In the last step of the evaporation process, PS particles motion is clearly visible (see supporting videos). PS particles flow is directed towards the droplet corners. The flow rates increase as the corners of the droplet contact line become sharper. Surface H5 shows the lowest amount of PS particles deposits at corners of the droplet perimeter (Figure 7(a)), whereas a higher concentration of PS particles was seen for the H15 substrate (Figure 7(c)).

Figures 7(a), (b) and (c) are taken from the PS particles supporting videos at the last moment of evaporation for $\mathrm{H} 5, \mathrm{H} 10$ and $\mathrm{H} 15$ substrate, respectively. The PS particles tend to accumulate in rounded corners close to the contact line as in H5 (Figure 7(a)) with a fewer PS particles accumulating in the sharper corners for H10 \& H15 (Figures 7(b) \& (c)). Note that 
the flow is so strong that in case of Figure 7(b) and (c) the contact line is stretched beyond its pinning position. Due to the enhanced flow towards the corners, those particles that do not reach the contact line are distributed along the surface forming an ' $\mathrm{X}$-shape'. This illustrated in Figure 7(d).

To quantify the surprising correlation found between the particle accumulation at the corners and the micropillar height, we measure the fluorescent light intensity emitted by the PS particles at different locations of the droplet at different time point during evaporation. The aim is to quantify the particle enrichment at the droplet corners and the depletion at its sides through the fluorescence light intensity, which is directly proportional to the amount of particles. Note that the measurements start at $80 \%$ of the total evaporation time. At this time the coffee-stain effect has been already able to drag a large amount of particles to the contact line. Therefore, all intensity profiles show a sharp increase as $r / R$ approaches 1 (with $r$ the distance to the contact line and $R$ the droplet radius), i.e. as we reach the droplet's contact line. If we focus our attention first on the droplet side perimeter, in Figure 8(a) and (c) we see that in both cases (droplets in $\mathrm{H} 5$ and $\mathrm{H} 15$, respectively), there is a clear decrease of the light intensity as the time reaches the final evaporation time (a 50\% decrease in $\mathrm{H} 5$ and about $75 \%$ decrease in $\mathrm{H} 15$ ). This means that particles are being "removed" from the side of the droplet as the solvent evaporates. Now we focus on the fluorescent intensity change at the corners of the droplets in Figures 8(b) and (c) for droplets on H5 and H15, respectively. Here, we clearly observe an opposite effect: the fluorescence intensity increases in almost $100 \%$ from the first time point measured. This intensity increase at the corners is due to the particle enrichment in the formed polygonal droplets. Note that despite the sharper corners in H15 (Figure 8(d)), the increase in intensity is comparable to the H5 case (Figure $\mathbf{8}(\mathbf{b})$ ). This is attributed to a large amount of particles in the $\mathrm{H} 15$ travelling beyond the pinning line and go beyond the measurement area (shown in Figure 7(c)). 


\subsection{Interpretation of the experimental results and physical explanation}

In previous sections we have shown a clear correlation between the accumulation of particles and bacteria at the corners of polygonal droplets. Additionally, surfaces with taller pillars show a larger deposits accumulating at the corners.

In the first time point measured after droplet deposition on the substrate, the droplet experiences a wetting transition from a Cassie-Baxter state to a lower-energy Wenzel state by filling the interspace between the micropillars. Under special geometric conditions and solvents, the liquid front advances through the pillar array in a step-wise manner known as zipping-wetting, that gives the polygonal shape to the droplet's perimeter. It is well-known that surfaces with taller micropillars present sharper corners. ${ }^{1-3}$ The reason is connected with the smaller curvature that the liquid menisci are able to adopt when the pillars are higher. The contact line remains pinned for practically entire process.

In sessile droplets, the evaporation occurs preferentially at the contact line ${ }^{6}$ and consequently a capillary flow develops and transports liquid and particles to the droplet's perimeter. Such flow drags the particles or bacteria towards the perimeter, explaining the high fraction found at the borders of the droplet. This phenomenon, known as the 'coffee-stain effect' explains the ring-shaped stains formed by the evaporation of a suspension droplet on flat substrates.

The evaporative flux $(J)$ at the droplet's surface depends on the distance from the contact line $r$. For the case of very thin droplets the flux takes the form $J(r) \sim D C_{s} / R(r / R)^{-0.5}$, where $D$ is the vapor diffusivity, $C_{s}$ is the vapor concentration difference, $R$ is the droplet radius and $r$ is a radial distance from the contact line.

The evaporation process changes dramatically when the contact line curves develop "angular regions" as described by Popov and Witten. ${ }^{61}$ They analyzed an idealized case of a perfectly 
sharp corner (curvature radius $R_{c}=0$ in Scheme 1). They demonstrated analytically that the evaporative flux near an angular region is strongly enhanced with respect to a straight contact line. This is expressed as $J \sim D C_{s} / R(r / R)^{-0.7}$ for an angular wedge of angle $\alpha=90^{\circ}$. Here, we estimate the outer length scale to be the size of the drop. Therefore, a particle in an evaporating square-shaped droplet feels a preferential flow towards the corners (see Figure 8). The angular region at the corner of the droplet is smoothened on a scale $r \sim R_{c}$, i.e. the curvature is not apparent when one sits very close to the corner. At such a scale, we should recover the square root behavior $J \sim D C_{s} / R_{c}\left(r / R_{c}\right)^{-0.5}$, but now with $R_{c}$ as the relevant scale.

Assuming that the flow velocity is directly proportional to the evaporative flux ${ }^{6} \mathrm{~J}$, we compare the flow towards the corners against the flow towards the straight contact line regions. Then, we can conclude that there is a flow enhancement towards the corners by a factor $(\mathrm{R} / \mathrm{Rc})^{1 / 2}$, that in our case is of the order of 10 for the sharpest droplets. Consequently, the smaller the contact line curvature radius $R_{c}$ is, the larger its influence in the generated flow towards the corners. Note that the smallest $R_{c}$ that can be achieved is limited by the diameter of the smallest microstructure holding the contact line. In this particular case, the pillars have typical diameters of $5 \mu \mathrm{m}$ (therefore $R_{c}=5 \mu \mathrm{m}$ ), while the droplets have typical radius, $R$, of $1 \mathrm{~mm}$.

\section{Conclusions}

The evaporation of induced bacterial patterns over micropillared substrates was studied. Variations in the shape of the deposition patterns are achieved by changing the pillar height of the fabricated micropatterns. We show that the non-axisymmetric evaporation process is found to be responsible for the inhomogeneous deposition of particles along the droplets perimeter. This is a result of the combined action of the coffee-stain effect and the zipping-wetting effect which results in the breakdown of symmetry of the perimeter of the droplet. Variations in bacterial distribution are explained by the enhanced evaporation-induced flow towards the 
corners of the polygonal droplets on the substrates. We observed a sharp difference in the type of local environment, as the pillar height is increased. The H15 substrates induce the deposition of bacteria into environments with high local concentration of cells. On the other hand, on the smaller pillar heights a lower local concentration environment is favored. Our results indicate that low height microstructured surfaces can lower bacterial regrowth and biomass attachment. These findings could be utilized for the design of novel topographical antimicrobial surfaces. 


\section{References}

1. Sbragaglia, M.; Peters, A. M.; Pirat, C.; Borkent, B. M.; Lammertink, R. G. H.; Wessling, M.; Lohse, D. Spontaneous breakdown of superhydrophobicity, Phys. Rev. Lett. 2007, 99, 156001

2. Pirat, C.; Sbragaglia, M.; Peters, A. M.; Borkent, B. M.; Lammertink, R. G. H.; Wessling, M.; Lohse, D. Multiple time scale dynamic in the breakdown of superhydrophobicity, EPL 2008, 81,66002

3. Peters, A. M.; Pirat, C.; Sbragaglia, M.; Borkent, B. M.; Wessling, M.; Lohse, D.; Lammertink, R. G. H. Cassie-Baxter to Wenzel state wetting transition: scaling of the front velocity, Eur. Phys. J. E 2009, 29, 391-397

4. Courbin, L.; Denieul, E.; Dressaire, E.; Roper, M.; Ajdari, A.; Stone, H. A. Imbibition by polygonal spreading on microdecorated surfaces, Nature Materials 2007, 6, 661-664

5. Raj, R.; Adera, S.; Enright, R.; Wang, E. N.; High-resolution liquid patterns via threedimensional droplet shape control, Nature Comm. 2014, 5, 4975

6. Deegan, R. D.; Bakajin, O.; Dupont, T.; Huber, G.; Nagel, S.; Witten, T. Capillary flow as the cause of ring stains from dried liquid drops, Nature 1997, 389, 827-829

7. Tani, M.; Kawano, R.; Kamiya, K.; Okumura, K. Towards combinatorial mixing devices without any pumps by open-capillary channels: fundamentals and applications, Scientific Reports 2015, 5, 10263

8. Fox, M.; Esveld, E.; Luttge, R.; Remko, B. A new pulsed electric field microreactor: comparison between the laboratory and microtechnology scale, Lab Chip 2005, 5, 943-948

9. Lemée, F.; Clarot, I.; Ronin, L.; Aranda, L.; Mourer, M.; Regnouf-de-Vains, J.-B. A bacteriophilic resin, synthesis and E. coli sequestration study, New J. Chem. 2015, 39, 2123-2129 
10. Scheuerman, T. R.; Camper, A. K.; Hamilton, M. A. Effects of substratum topography on bacteria adhesion, Journal of colloids and interface science 1998, 208, 23-33

11. Merian, T.; Goddard, J. M.; Advances in nonfouling materials: perspectives for the food industry, Journal of Agricultural and Food Chemistry 2012, 60, 2943-2957

12. Crawford, R. J.; Webb, H. K.; Truong, V. K.; Hasan, J.; Ivanova, E. P. Surface topographical factors influencing bacterial attachment, Advances in Colloids and Interface Science 2012, 179-182, 142-149

13. Duncan, T. V.; Applications of nanotechnology in food packaging and food safety: Barrier materials, antimicrobials and sensors, Journal of Colloid and Interface Science 2011, 363, $1-24$

14. Desrousseaux, C.; Sautou, V.; Descamps, S.; Traor, O. Modification of the surfaces of medical devices to prevent microbial adhesion and biofilm formation, Journal of Hospital Infection 2013, 85, 87-93

15. National Nosocomial Infections Surveillance (NNIS) System Report, data summary from January 1992 through June 2004, issued October 2004. Am. J Infect Control. 2004, 32, $470-485$

16. Renner, L. D.; Weibel, D. B. Physicochemical regulation of biofilm formation, MRS bulletin 2011, 36, 347-355

17. Hochbaum, A. I.; Aizenberg, J. Bacteria pattern spontaneously on periodic nanostructure arrays, Nano Lett. 2010, 10, 3717-3721

18. Allion, A.; Baron, J.-P.; Boulange-Petermann, L. Impact of surface energy and roughness on cell distribution and viability, Biofouling 2006, 22, 269-278

19. Medilanski, E.; Kaufmann, K.; Wick, L. Y.; Wanner, O.; Harms, H. Influence of the cell surface topography of stainless steel on bacterial adhesion, Biofouling 2002, 18, 193-203 
20. Bruzaud, J.; Tarrade, J.; Coudreuse, A.; Canette, A.; Herry, J.-M.; de Givenchy, E. T.; Darmanin, T.; Guittard, F.; Guilbaud, M.; Bellon-Fontaine, M.-N. Flagella but not type IV pili are involved in the initial adhesion of Pseudomonas aeruginosa PAO1 to hydrophobic or superhydrophobic surfaces, Colloids and Surfaces B: Biointerfaces 2015, 131, 59-66

21. Xu, L.-C.; Siedlecki, C. A. Staphylococcus epidermidis adhesion on hydrophobic and hydrophilic textured biomaterials, Biomed. Mater. 2014, 9, 035003

22. Perera-Costa, D.; Morales Bruque, J.; González-Martín, M. L.; Gómez-García, A. C.; Vallido-Rodríguez, V. Studying the influence of Surface topography on bacterial adhesion using specially organized microtopographic surface patters, Langmuir 2014, 30, 4633-4641

23. Tsai, P.; Lammertink, R. G. H.; Wessling, M.; Lohse, D. Evaporation-triggered wetting transition for water droplets upon hydrophobic microstructures, Physical Review Letters 2010, 104,116102

24. Papadopoulos, P.; Mammen, L.; Deng, X.; Vollmer, D.; Butt, H.-J. How superhydrophobicity breaks down, Proc. Natl. Acad. Sci. USA 2013, 110, 3254-3258

25. Dietrich, S.; Popescu, M. N.; Rauscher, M.; Wetting on structured substrates, J. Phys.: Condens. Matter 2005, 17, S577-S593

26. Bonn, D.; Eggers, J.; Indekeu, J.; Meunier, J.; Rolley, E. Wetting and spreading, Rev. Mod. Phys. 2009, 81, 739-805

27. Susarrey-Arce, A.; Marin, A. G.; Schlautmann, S.; Lefferts, L.; Gardeniers, J. G. E.; van Houselt, A. One-step sculpting of silicon microstructures from pillars to needles for water and oil repelling surfaces, J. Micromech. Microeng. 2013, 23, 025004

28. Marin, A. G.; Gelderblom, H.; Susarrey-Arce, A.; van Houselt, A.; Lefferts, L.; Gardeniers, J.G.E.; Lohse, D.; Snoeijer, J. H. Building microscopic soccer balls with evaporating colloidal fakir drops, Proc. Natl. Acad. Sci. USA 2012, 109, 16455-16458 
29. Barbieri, L.; Wagner, E.; Hoffmann P.; Water Wetting transition parameters of perfluorinated substrates with periodically distributed flat-top microscale obstacles, Langmuir 2007, 23, 1723-1734

30. Guoping, F.; Amirfazli, A. Understanding the edge effect in wetting: a thermodynamic approach, Langmuir 2012, 28, 9421-9430

31. Susarrey-Arce, A.; Marín, A. G.; Nair, H.; Lefferts, L.; Gardeniers, J. G. E.; Lohse, D.; van Houselt, A. Absence of an evaporation-driven wetting transition on omniphobic surfaces, Soft Matter 2012, 8, 9765-9770

32. do Nascimento, R. M.; Cottin-Bizonne, C.; Pirat, C.; Ramos S. M. M. Water Drop Evaporation on Mushroom-like Superhydrophobic Surfaces: Temperature Effects, Langmuir 2016, 32, 2005-2009

33. Reyssat, M.; Yeomans, J. M.; Quéré, D. Impalement of fakir drops, EPL 2008, 81, 26006

34. Chuang, Y.-C.; Chu, C.-K.; Lin, S.-Y., Chen, L.-J. Evaporation of water droplets on soft patterned surfaces, Soft Matter 2014, 10, 3394-3403

35. Boreyko, J. B.; Baker, C. H., Poley, C. R., Chen, C.-H. Wetting and Dewetting Transitions on Hierarchical Superhydrophobic Surfaces, Langmuir 2011, 27, 7502-7509

36. Xie, X.; Li, Y.; Zhang, T.; Fang, H. H. P. Bacterial survival in evaporating deposited droplets on a teflon-coated surface, Appl. Microbiol Biotechnol. 2006, 73, 703-712

37. Nellimoottil, T. T.; Rao, P. N.; Ghosh, S. S.; Chattopadhyay, A. Evaporation-induced patterns from droplets containing motile and nonmotile bacteria, Langmuir 2007, 23, 86558658

38. Jerrim, L. B.; Velev, O. D. Deposition of coating from live cells and large particles by “convective-sedimentation” assembly, Langmuir 2009, 25, 5692-5702

39. Baughman, K. F.; Maier, R. M.; Norris, T. A.; Beam, B. M.; Mudalige, A.; Pemberton, J. E.; Curry, J. E. Evaporative deposition patterns of bacteria from sessile drop: effect of 
changes in surface wettability due to exposure to a laboratory atmosphere, Langmuir $\mathbf{2 0 1 0}$, $26,7293-7298$

40. Sempels, W.; De Dier, R.; Mizuno, H.; Hofkens, J.; Vermant, J. Auto-production of biosurfactants reverses the coffee ring effect in a bacterial system, Nature Comm. 2013, 4, 1757

41. Marin, A.; Gelderblom, H.; Lohse, D.; Snoeijer, J. H. Order-to-disorder transition in ringshaped colloidal stains, Phys. Rev. Lett. 2011, 107, 085502

42. O'Toole, G. A. Microtiter dish biofilm formation Assay, J. Vis. Exp. 2011, 47, e2437

43. de Gennes, P.-G.; Brochard-Wyart, F.; Quéré, D. Capillarity and Wetting Phenomena: Drops, Bubbles, Pearls, Waves, Springer-Verlag, New York, 2004, ISBN 0-387-00592-7

44. Reyssat, M.; Quéré, D. Contact angle hysteresis generated by strong dilute defects, J. Phys. Chem. B 2009, 113, 3906-3909

45. Yeh, Y.-H.; Cho, K.-H.; Chen, L.-J. Effect of softness of polydimethylsiloxane on the hydrophobicity of pillar-like patterned surfaces, Soft Matter 2012, 8, 1079-1086

46. Pericet-Camara, R.; Auernhammer, G. K.; Koynov, K.; Lorenzoni, S.; Raiteric, R.; Bonaccurso, E.; Soft Matter 2009, 5, 3611-3617

47. Krepsky, N.; Barreto, R.; Ferreira, R.; Nunes, A. P. F.; Lins, U. G. C.; Filho, F. C. S.; de Mattos-Guaraldi, A. L.; Netto-dosSantos, K. R. Cell surface hydrophobicity and slime production of Staphylococcus epidermidis Brazilian isolates, Current Microbiology 2003, $46,280-286$

48. Rosenberg, M.; Gutnick, D.; Rosenberg, E. Adherence of bacteria to hydrocarbons: a simple method for measuring cell-surface hydrophobicity, FEMS Microbiology Letters 1980, $9,29-33$

49. Israelachvili, J. N.; McGuiggan, P. M. Forces between surfaces in liquids, Science 1988, $241,795-800$ 
50. Marin, A.; Liepelt, R.; Rossi, M.; Kähler C. J. Surfactant-driven flow transitions in evaporating droplets, Soft Matter 2016, 12, 1593-1600

51. Hernández-Sánchez, J. F.; Eddi, A.; Snoeijer, J. H. Marangoni spreading due to a localized alcohol supply on a thin water film, Phys. Fluids 2015, 27, 032003

52. Thokchom, A. K.; Swaminathan, R.; Singh, A. Fluid flow and particle dynamics inside an evaporating droplet containing live bacteria displaying chemotaxis, Langmuir 2014, 30, $12144-12153$

53. Otto, M., Staphylococcal Biofilms, Curr Top Microbiol Immunol. 2008, 322, 207-228

54. Heilmann, C.; Hussain, M.; Peters, G.; Götz, F., Evidence for autolysin-mediated primary attachment of Staphylococcus epidermidis to a polystyrene surface, Molecular Microbiology 1997, 24, 1013-1024

55. Susarrey-Arce, A.; Sorzabal-Bellido, I.; Oknianska, A.; McBride, F.; Beckett, A. J.; Gardeniers, J. G. E.; Raval, R.; Tiggelaar, R.; Diaz Fernandez, Y. A. Bacterial viability on chemically modified silicon nanowire arrays, J. Mat. Chem. B 2016, 4, 3104-3112

56. Graham, M. V.; Cady, N. C. Nano and microscale topographies for the prevention of bacterial surface fouling, Coatings 2014, 4, 37-59

57. Graham, M. V.; Mosier, A. P.; Kiehl, T. R.; Kaloyeros, A. E.; Cady, N. C. Development of antifouling surfaces to reduce bacterial attachment, Soft Matter 2013, 9, 6235-6244

58. Schumacher, J. F.; Carman, M. L.; Estes, T. G.; Feinberg, A. W.; Wilson, L. H.; Callow, M. E.; Callow, J. A.; Finlay, J. A.; Brennan, A. B. Engineered antifouling microtopographies-effect of feature size, geometry, and roughness on settlement of zoospores of the green alga Ulva, Biofouling 2007, 23, 55-62

59. Wenzel, R. N. Resistance of solid surfaces to wetting by water, Ind. Eng. Chem. 1936, 28, 988-994

60. Bico, J.; Tordeux, C.; Quere, D. Rough wetting, Europhys. Lett. 2001, 55, 214-220 
61. Popov, Y. O.; Witten, T. A. Characteristic angles in the wetting of an angular region: deposit growth, Physical Review E 2003, 68, 036306

\section{Acknowledgements}

We acknowledge Dr. Marco Marcello and Dr. Joanna Wnetrzak from Liverpool Centre for Cell Imaging (CCI) for provision of imaging equipment and technical assistance as well as Nanoinvestigation Centre for access to the facility. The authors also express their gratitude to

S. Schlautmann, M. Bos and G. W. Bruggert from University of Twente for technical support. This work was partly founded by EPSRC grant number EP/J019364/1. 


\section{Figures and captions}

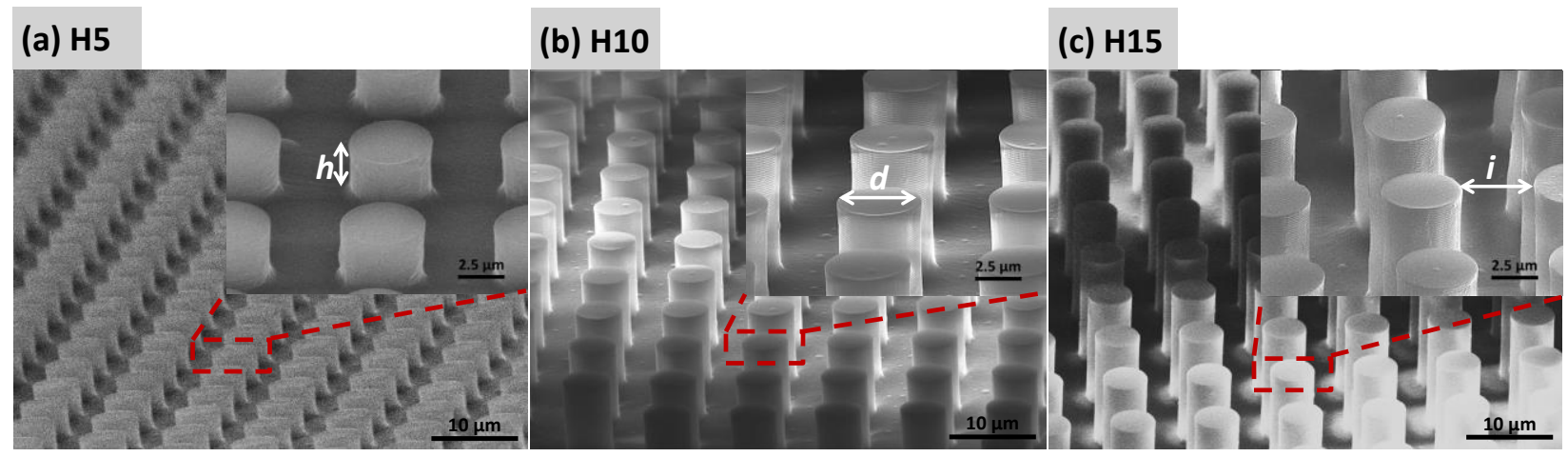

Figure 1. SEM images of substrates with micropillars: (a) $5 \mu \mathrm{m}$ height (H5), (b) $10 \mu \mathrm{m}$ height (H10), and (c) $15 \mu \mathrm{m}$ height (H15). 


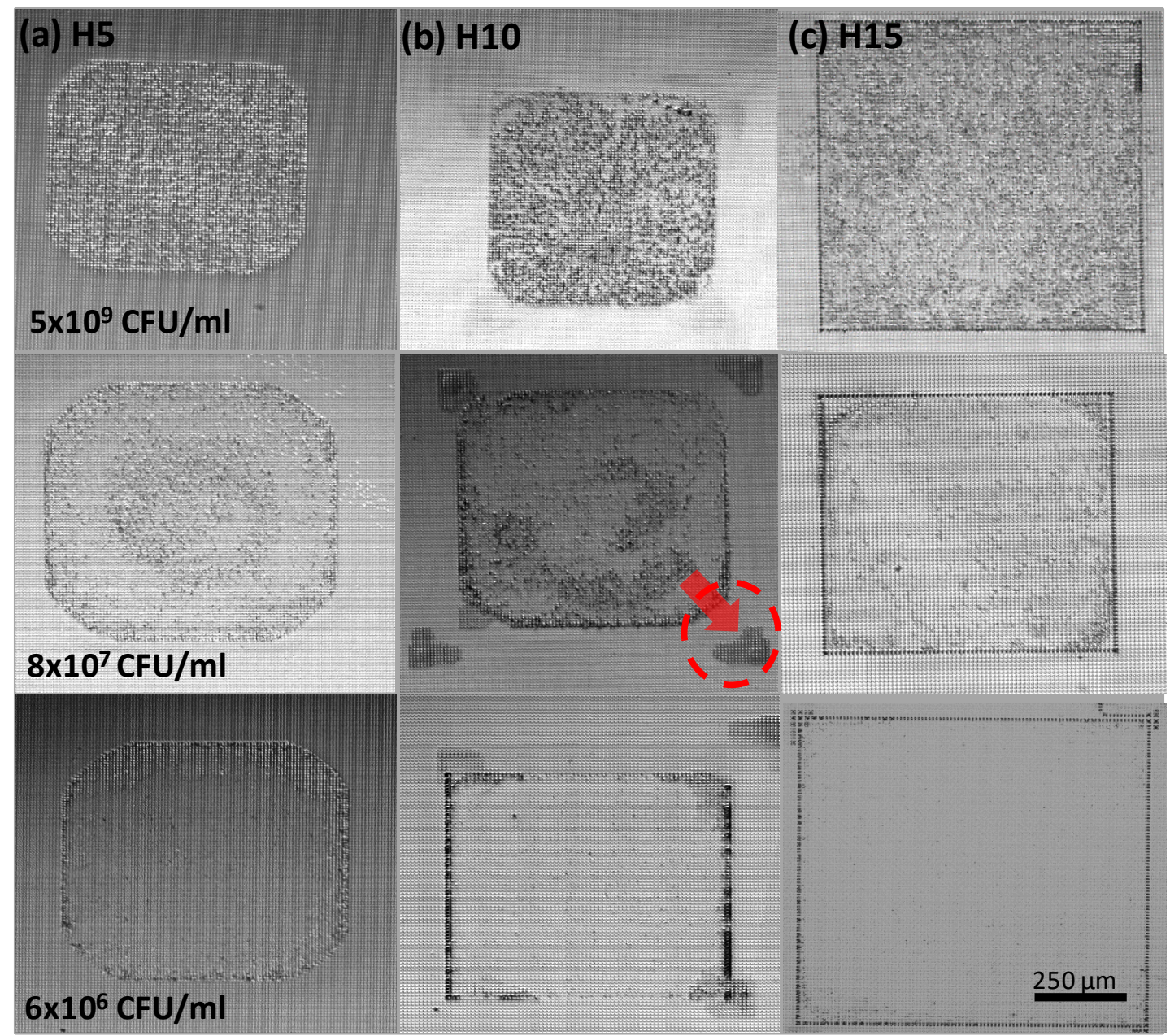

Figure 2. Images of the resulting patterns formed after the evaporation of S. epidermidis droplets containing 5.0x $10^{9} \mathrm{CFU} / \mathrm{mL}$ (first row), $8.0 \times 10^{7} \mathrm{CFU} / \mathrm{mL}$ (second row) and $6.3 \times 10^{6}$ CFU/mL (third row) over (a) H5, (b) H10 and (c) H15 substrates. For all substrates, the scale bars in the light microscope images represent $250 \mu \mathrm{m}$. In addition, S. epidermidis stain outside of the original square pattern and is highlighted in red in (b). 


\section{H15 S. epidermidis}

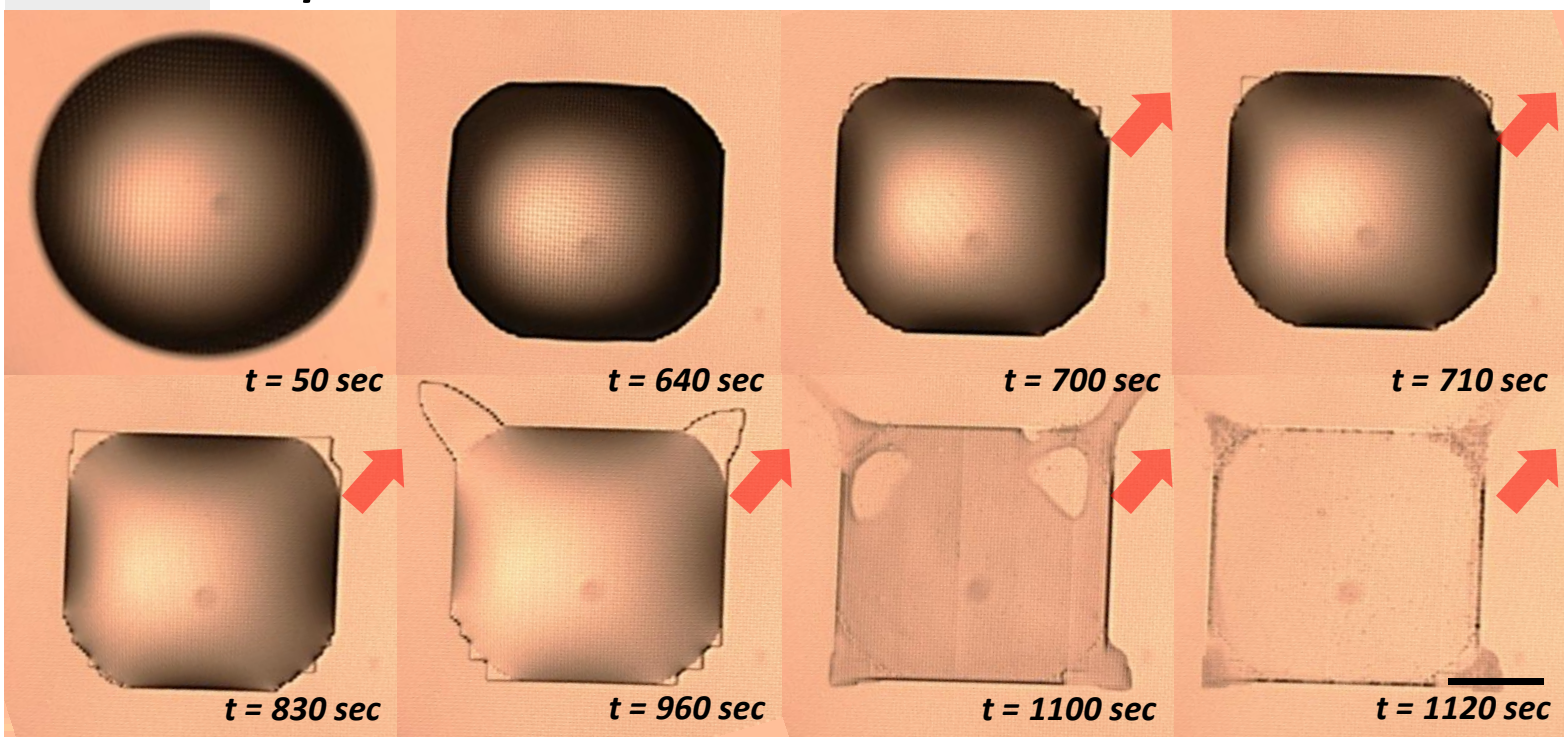

Figure 3. Top-view images of a droplet containing $\sim 8 \times 10^{7} \mathrm{CFU} / \mathrm{mL}$ S. epidermidis deposited and evaporated over H15 surface. Direction of zipping-wetting effect is highlighted with a red arrow. The scale bar at the bottom right represents $250 \mu \mathrm{m}$. 


\section{(a) S. epidermidis}

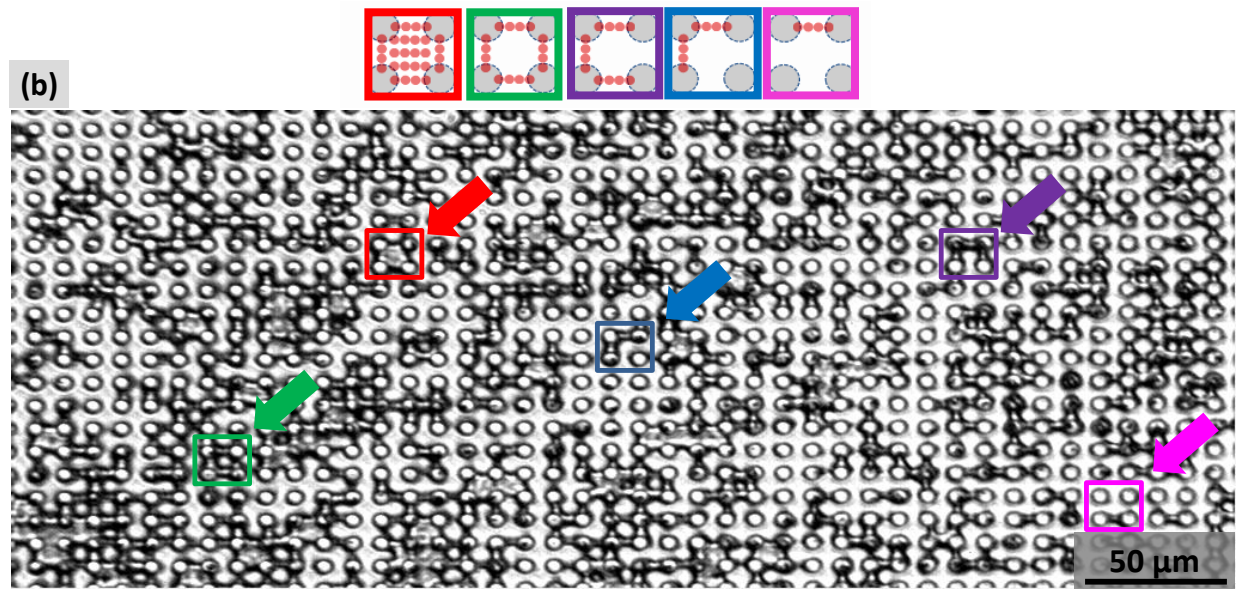

(c)

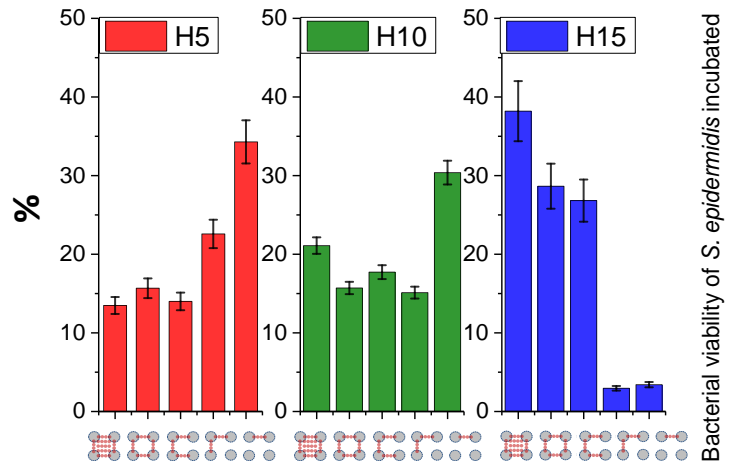

(d)

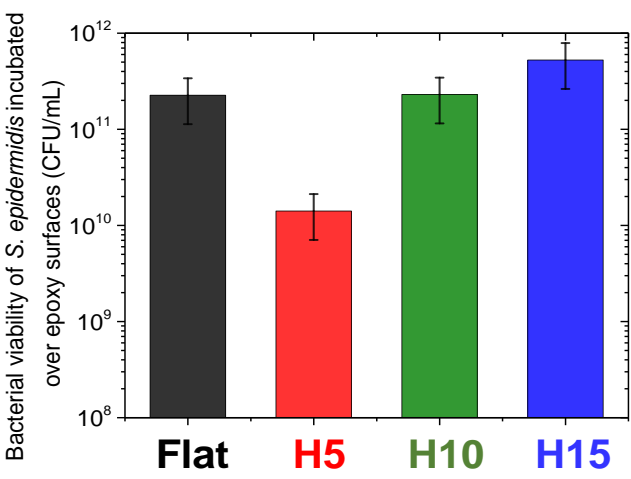

Figure 4. (a) Sketch of drying patterns of evaporated droplets with S. epidermidis between micropillar troughs. From left to right: completely filled structure, square lattice with empty central space, bacteria in "C" shape, bacteria in "L" shape and "I" single line of bacteria. (b) Representative bright field modular microscope image of an evaporated droplet area over H5 containing S. epidermidis patterns. Highlights represent a bacterial environment for each category identified by color in (a-b). (c) Chart of the percentage of S. epidermidis patterns deposited in H5, H10 and H15. (d) Count number of viable S. epidermidis cells recovered after $24 \mathrm{~h}$ after rehydration on flat surface and on substrates decorated with micropillars H5, H10 and H15. Experiments in (c) were performed in triplicates by drying ten to twenty independent droplets over substrates. The number of pattern in (c) was estimated from five entire evaporated droplets per dried substrate. Microbiological test in (d) were carried out independently in triplicates. Values in (c) and (d) were expressed \pm SD. 


\section{H5}

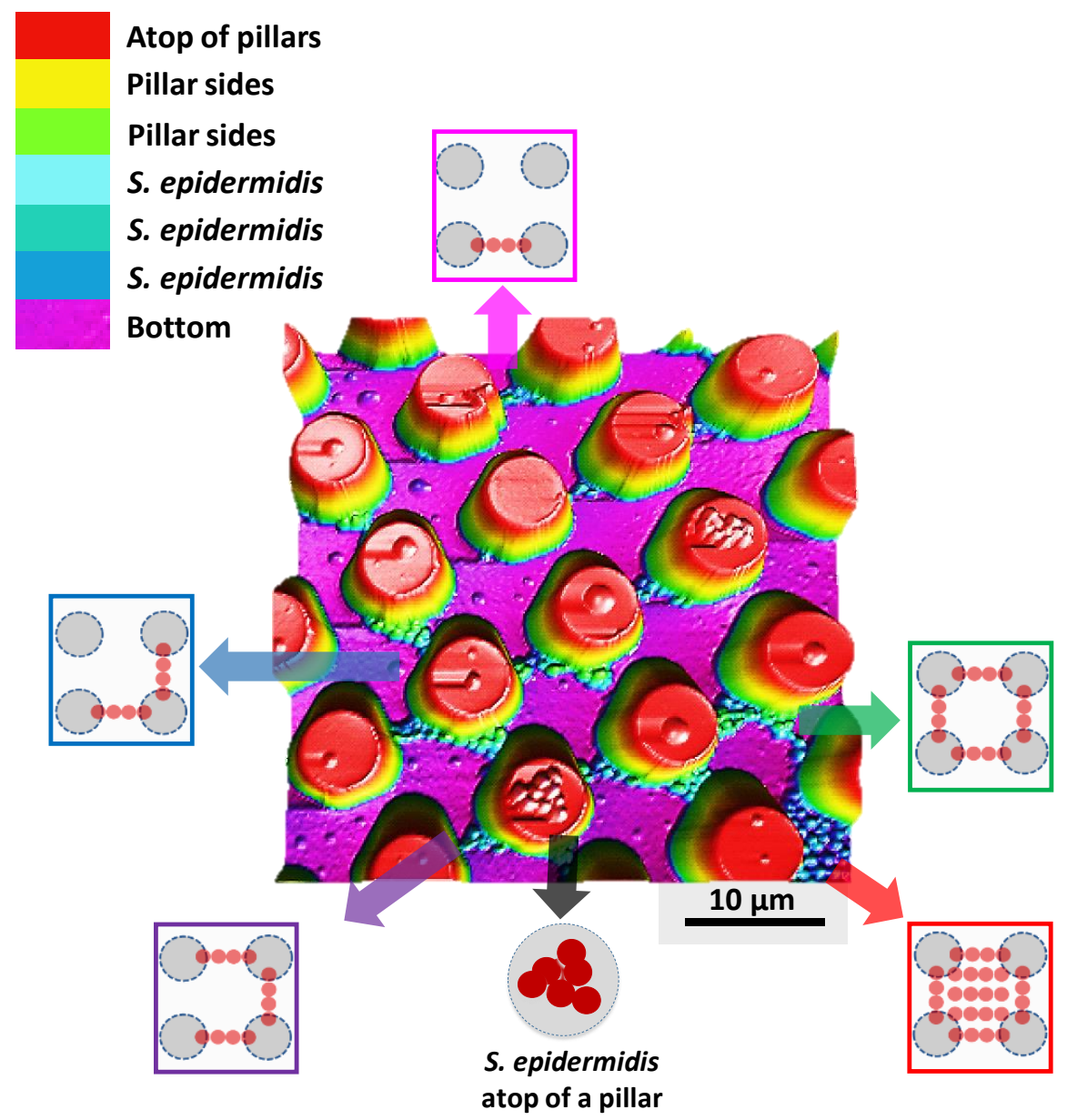

Figure 5. 3D-AFM image of a H5 surface with S. epidermidis patterns deposited at the bottom of the troughs and atop of pillars. Patterns formed by S. epidermidis are highlighted with colored arrows as shown in Figures 4(a) and 4(b). Note that from 3D-AFM image, the lower plane between the micropillars troughs is purple and bacteria on the floor of the surface are in blue colors. 

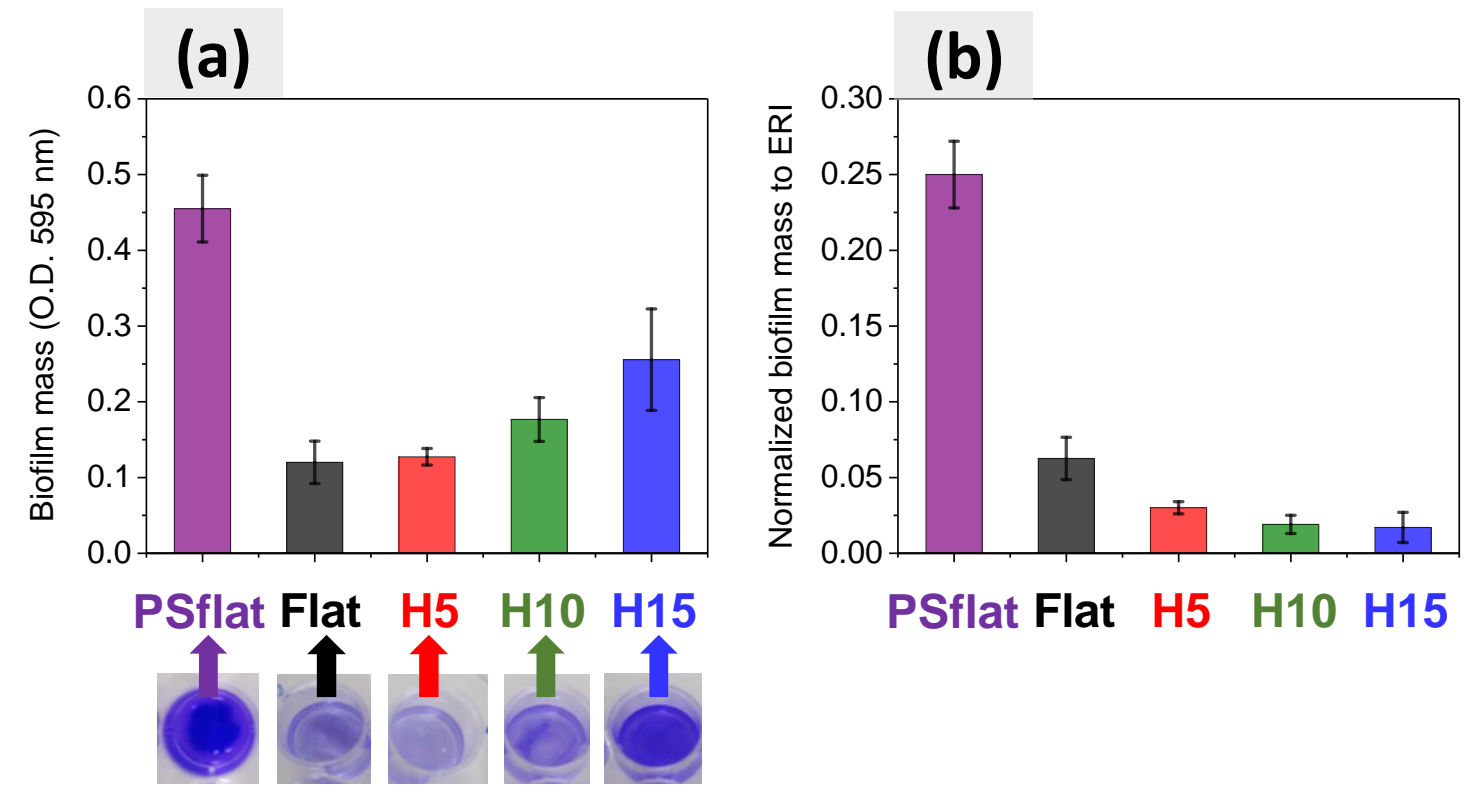

Figure 6. (a) Biofilm formation assay with S. epidermidis cultured for $24 \mathrm{~h}$ over surfaces: polystyrene flat (PSflat), flat epoxy (Flat), H5, H10 and H15. (b) Normalized biofilm mass to ERI for PSflat, Flat, H5, H10 and H15. Three independent experiments were performed. All values are expressed $\pm \mathrm{SD}$. 


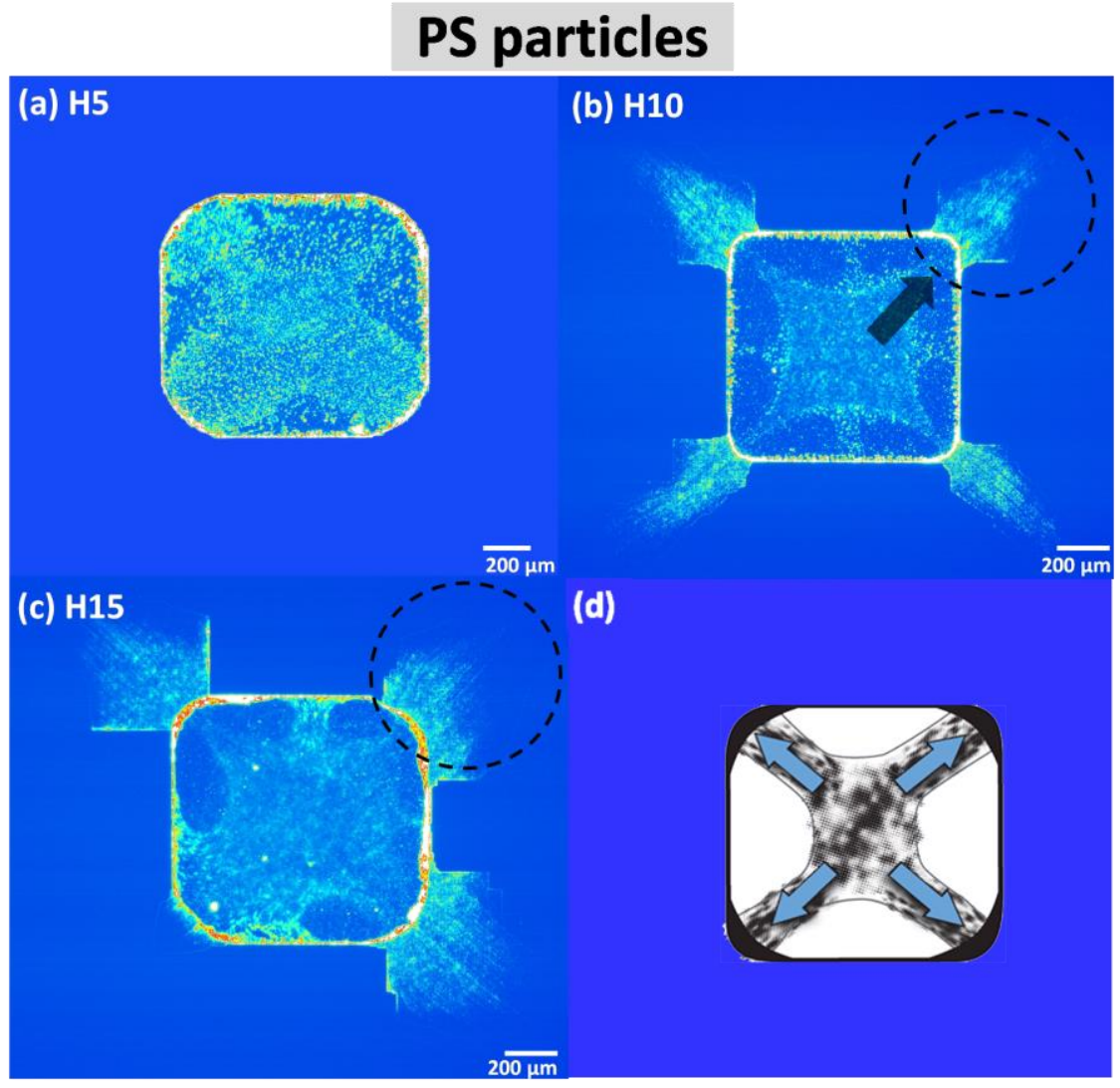

Figure 7. Drying patterns from evaporated droplets containing PS particles on (a) H5, (b) H10 and (c) H15 substrates. (d) Preferential direction drawing of the capillary-driven flow is highlighted with blue arrows. In addition, fluorescent particles stretching outside of the original square patterns (see (b)-(c)) are highlighted with an open dashed circle. Preferential direction of the capillary driven flow contributing to the distribution of the particles is also highlighted with an arrow. 


\section{PS particles}

(a) $\mathrm{H} 5$

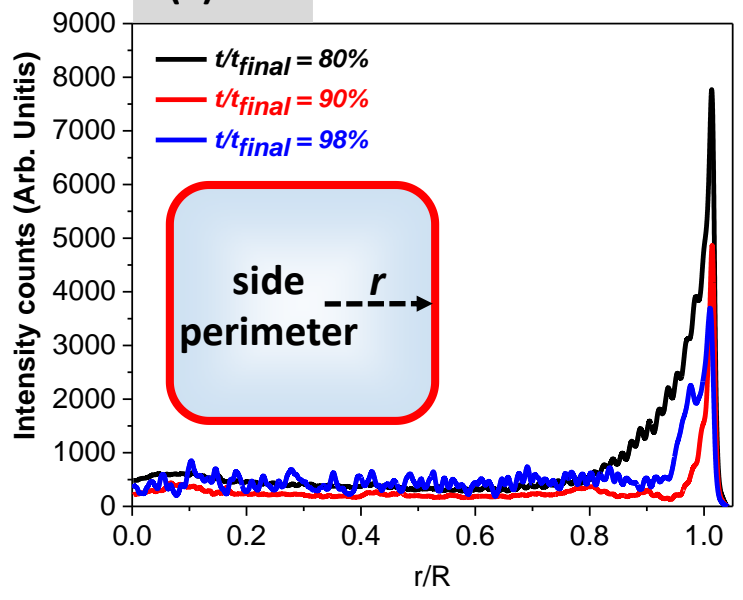

(c) $\mathrm{H} 15$

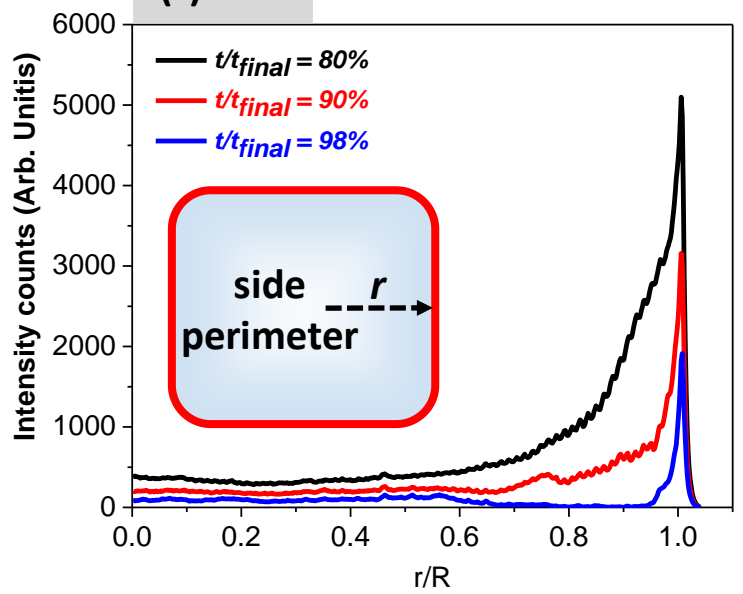

(b) $\mathrm{H} 5$

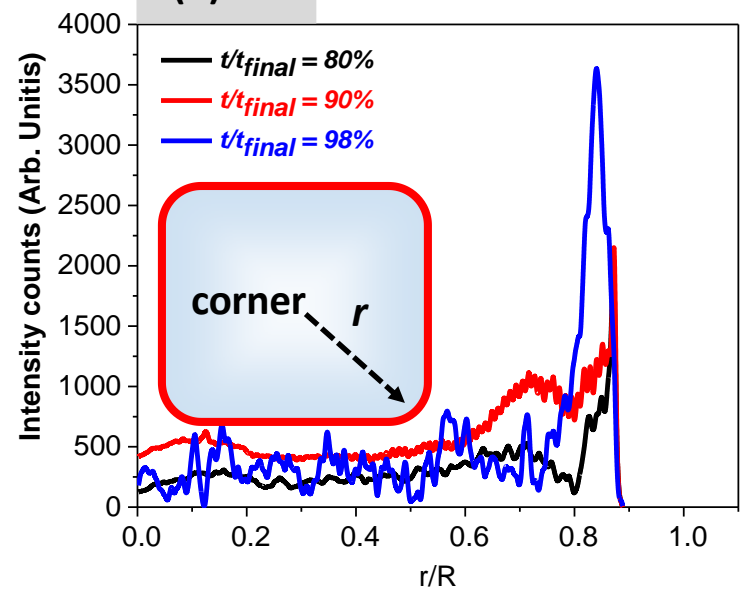

(d) $\mathrm{H} 15$

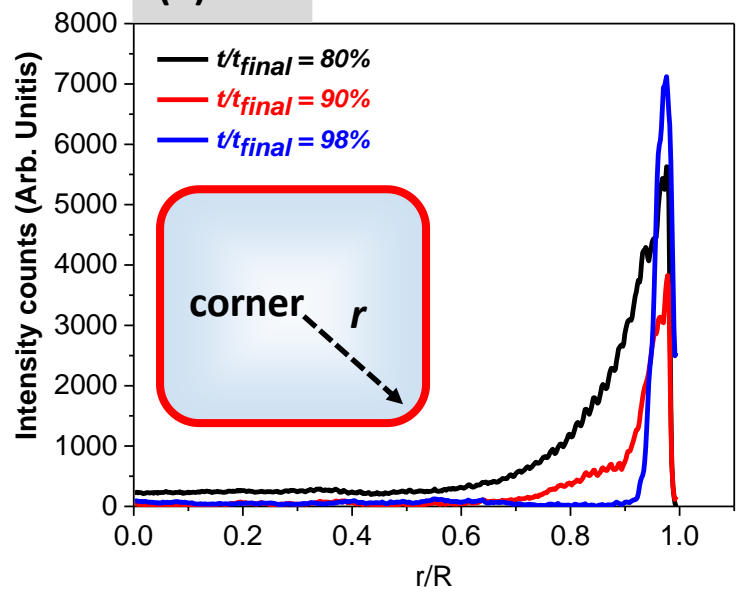

Figure 8. Fluorescent light intensity emitted by PS particles. The intensity is proportional to the particle density. Measurements in $(a, c)$ and $(b, d)$ were performed during drying of a droplet over substrate H5 \& H15, respectively. (a) \& (c) shows the intensity change from the center to the side perimeter of the droplet, while (b) and (d) show the intensity change from the center of the droplet to the corner. Intensity measurements are presented during last intervals before complete evaporation, e.g. 80\% (black line), 90\% (red line), and 98\% (blue line). 
(a)

(b)

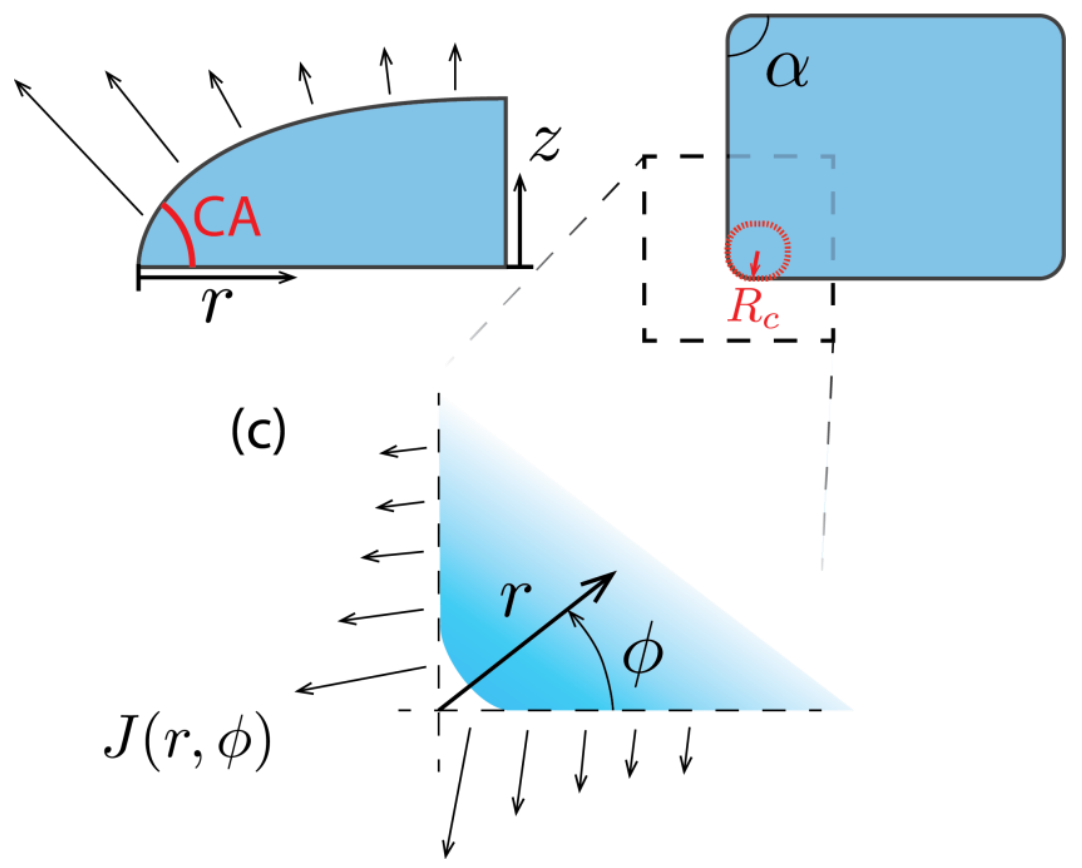

Scheme 1. (a) Side view of a deposited droplet on a substrate with a sharpness curvature and contact angle (CA) in $\boldsymbol{r}-\boldsymbol{z}$ planes (b) Top-view of a droplet with geometrical curvature in $\boldsymbol{r}-\boldsymbol{\Phi}$, $\boldsymbol{R}_{\boldsymbol{c}}$ is the corner's radius of curvature and $\boldsymbol{\alpha}$ is the wedge angle (c) Detail of the droplet corner: $\boldsymbol{r}$ is defined as the distance to the contact line and $\boldsymbol{J}$ is the evaporative flux. 


\section{Tables}

Table 1. Height $(h)$, pillar-to-pillar interspace $(i)$ and diameter $(d)$ of the microstructures on substrates (a)-(c)

\begin{tabular}{|c|c|c|c|}
\hline Microstructure & $\boldsymbol{h}(\boldsymbol{\mu m})$ & $\boldsymbol{i}(\boldsymbol{\mu m})$ & $\boldsymbol{d}(\boldsymbol{\mu m})$ \\
\hline (a) H5 & 4.8 & 4.7 & 5.0 \\
\hline (b) H10 & 9.5 & 4.5 & 5.0 \\
\hline (c) H15 & 15.7 & 5.0 & 5.2 \\
\hline
\end{tabular}


For table of content (TOC) use only

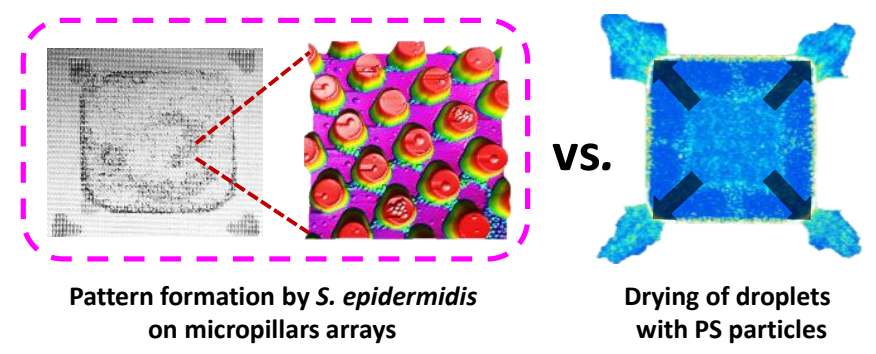

